\title{
Extracorporeal Hepatic Resection and Autotransplantation Using Temporary Portocaval Shunt Provides an Improved Solution for Conventionally Unresectable HCC
}

\author{
Pei-Hung Wen • Kuo-Hua Lin • Yao-Li Chen • \\ Chia-En Hsieh • Chih-Jan Ko • Shou-Jen Kuo
}

Received: 12 December 2012/ Accepted: 14 July 2013/Published online: 6 August 2013

(C) The Author(s) 2013. This article is published with open access at Springerlink.com

Keywords Extracorporeal hepatic resection · Autotransplantation · Hepatocellular carcinoma with difficult anatomy $\cdot$ Temporary portocaval shunt

Hepatic resection is the gold-standard treatment for hepatocellular carcinoma (HCC). In East Asia, however, only $20 \%$ of patients with $\mathrm{HCC}$ are eligible for hepatectomy [1]. In a small subset of patients, surgical resection using conventional techniques is extremely challenging. In these marginal cases, the tumor size, extension of the lesion, and proximity of the tumor to critical structures are important factors determining how to proceed. For tumors considered unresectable by conventional means, extracorporeal hepatic resection with autotransplantation (ECHRA) has been proposed to be an alternative [2].

ECHRA has been used to treat hepatic pathologies including giant hemangioma [3], liver metastases [4], and sarcomas [2]. However, few studies have reported on its application as a treatment for HCC [5]. Herein we report a case series involving three consecutive patients with HCC who were successfully treated with ECHRA as curative therapy for otherwise unresectable HCCs.

\section{Patient Selection and Pre-operative Evaluation}

In 2011, ECHRA was performed in three patients with liver tumors at anatomically critical locations that were deemed technically impossible to resect (Fig. 1). Patient

P.-H. Wen · K.-H. Lin $(\bowtie) \cdot$ Y.-L. Chen · C.-E. Hsieh ·

C.-J. Ko - S.-J. Kuo

Changhua Christian Hospital, Changhua City, Taiwan, ROC

e-mail: 120380@cch.org.tw characteristics and indications for this technique are outlined in Table 1. To ensure sufficient liver function after liver resection, we estimated pre- and post-operative liver volumes using 3-D computed tomography volumetry. Indocyanine green (ICG) test was performed in selected patients. None of the patients showed evidence of portal hypertension.

\section{Surgery}

ECHRA was performed as described previously with minor modifications [6]. Unlike previous reports, we employed temporary portocaval shunt during the anhepatic period (Fig. 2). In patients with tumor-invaded major vasculature, the vessel wall was pared and reconstruction with a venous patch harvested from the explanted liver (Fig. 3). Details of the surgery are given in Table 2 . The affected segments of liver were resected after total hepatectomy and the autograft was re-implanted orthotopically. Pathology evaluation confirmed all three tumors to be HCC.

\section{Results and Outcome}

The outcomes are outlined in Table 3. Patient 3 had major complications included postoperative biliary leakage and intra-abdominal abscess, which were treated with endoscopic retrograde cholangiopancreatography and surgical drainage of the abscess, respectively. There was no hospital mortality.

Two of the three patients experienced tumor recurrence 8 months after the operation. Patient 2 was treated with radiofrequency ablation while the other was treated by transarterial chemoembolization. All patients are currently alive with stable disease at the most recent follow-up. 


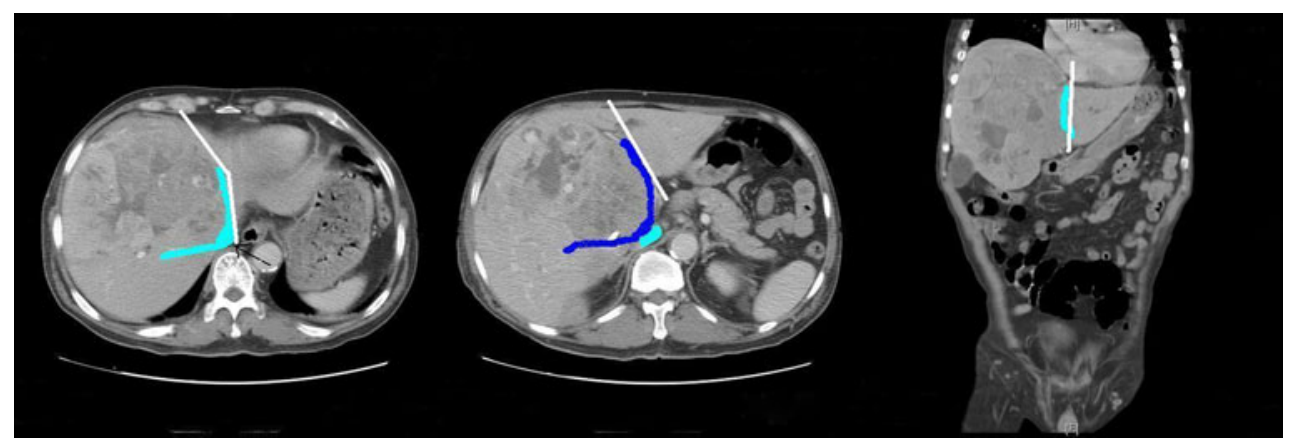

Fig. 1 CT images of case series. a Large liver tumor with compression of the IVC (arrow), left hepatic vein and right hepatic vein. The middle hepatic vein has been obscured. The resection line (white line) follows the left hepatic vein. b Both the portal vein (navy blue) and
IVC (dark blue) are compressed by the tumor. The resection line in this view follows the left portal vein. c Coronal illustration of the resection line (white line)

Table 1 Patient characteristics

ECOG Eastern Cooperative Oncology Group performance status, $P H$ portal hypertension, $S$ liver segment, $L H V$ left hepatic vein, $M H V$ middle hepatic vein, $I V C$ inferior vena cava, $V 7$ hepatic vein to segment 7, $R H V$ right hepatic vein, $P V$ portal vein

${ }^{\text {a }}$ Ratio of remnant liver volume and standard liver volume

\begin{tabular}{|c|c|c|c|}
\hline Patient characteristics & Patient 1 & Patient 2 & Patient 3 \\
\hline Age & 67 & 71 & 60 \\
\hline Sex & M & M & M \\
\hline ECOG & 0 & 0 & 0 \\
\hline \multicolumn{4}{|l|}{ Pre-operative data } \\
\hline Hepatitis history & $\begin{array}{l}\text { Non-B/C, } \\
\text { alcoholism }\end{array}$ & Hepatitis B & Hepatitis C \\
\hline AFP (ng/ml) & 357.59 & $>270,000$ & 24.25 \\
\hline Platelet count $(/ \mu \mathrm{l})$ & $227 \times 10^{3}$ & $335 \times 10^{3}$ & $380 \times 10^{3}$ \\
\hline INR & 1.22 & 1.28 & 0.93 \\
\hline Evidence of PH & No & No & No \\
\hline \multicolumn{4}{|l|}{ Tumor characteristics } \\
\hline Maximum diameter $(\mathrm{cm})$ & $18 \times 12$ & $18 \times 13$ & $5.8 \times 6.8$ \\
\hline Tumor location & S $1,4,5,7,8$ & S $2,3,4,5,8$ & $\begin{array}{l}\text { S } 4,5,8 \\
\text { Satellite S7 }\end{array}$ \\
\hline $\begin{array}{l}\text { Indication for ECHRA (vascular } \\
\text { involvement/tumor location) }\end{array}$ & $\begin{array}{l}\text { At confluence of } \\
\text { LHV, MHV, IVC }\end{array}$ & $\begin{array}{l}\text { At confluence of V7/ } \\
\text { RHV into IVC }\end{array}$ & $\begin{array}{l}\text { Centrally located, } \\
\text { involve RHV, PV }\end{array}$ \\
\hline Remnant liver volume $(\%)^{\mathrm{a}}$ & 44.26 & 34.46 & 51.00 \\
\hline
\end{tabular}
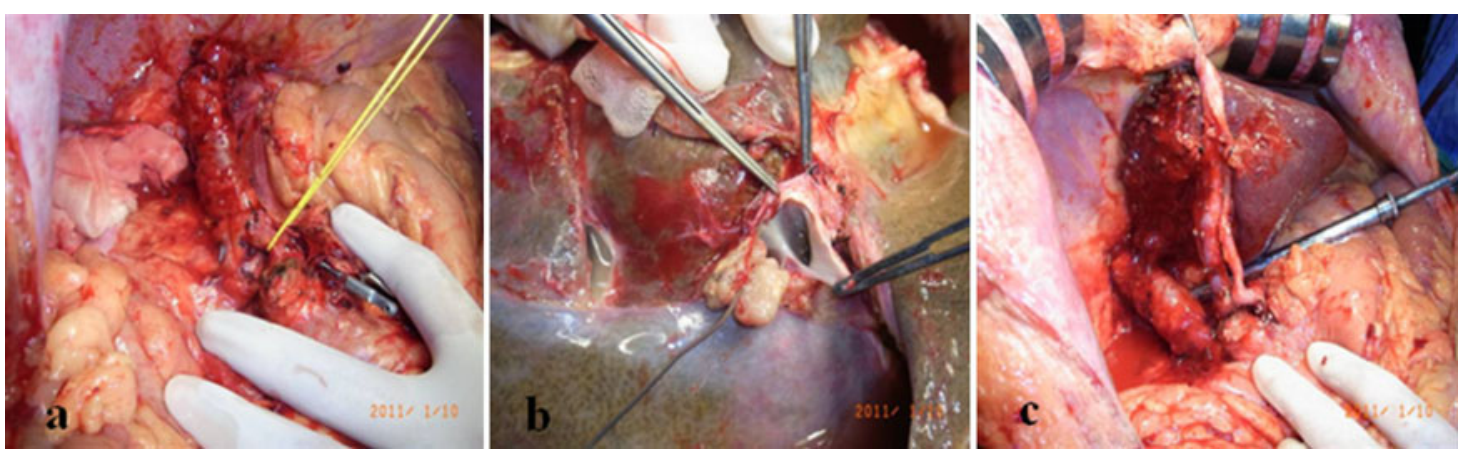

Fig. 2 a Temporary portocaval shunt used during the anhepatic period. b Tumor thrombus found in the confluence of the hepatic veins. c Re-implantation of the graft

To date, the only large series involving ECHRA was reported by Oldhafer et al. [7]. The difficulty of the surgical technique and the high perioperative and postoperative morbidity impede surgeons from using this procedure. We are the first institution to use preoperative liver volumetry to prevent postoperative hepatic failure, the most serious 

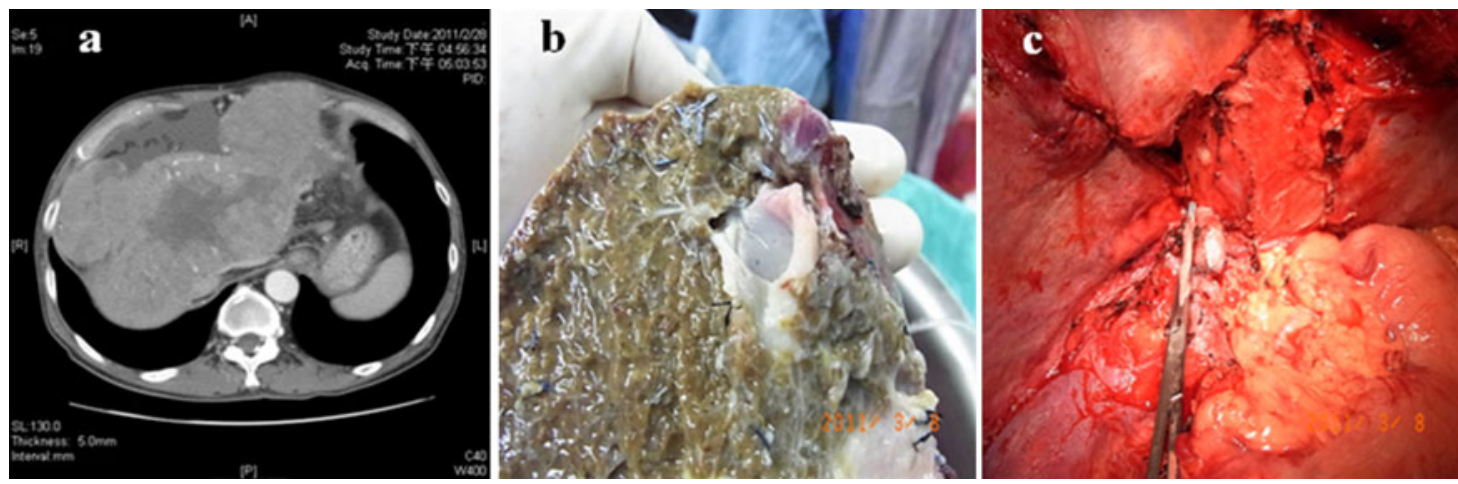

Fig. 3 a Large HCC compressing the juncture of left hepatic vein and IVC. b Part of the IVC wall was excised and repaired with a venous patch (arrow). c Unification of V7 and right hepatic vein, which was later widened with a venous patch

Table 2 Operation characteristics

\begin{tabular}{llll}
\hline Operation (OP) details & Patient 1 & Patient 2 & Patient 3 \\
\hline Replanted graft segments & $\begin{array}{c}\text { S 2, 3, and } \\
\text { partial S 4 }\end{array}$ & S 5-8 & S 2, 3, and \\
& 440 & 696 & S 6, 7 \\
Graft weight (g) & 1,500 & 5,300 & 7,000 \\
Blood loss (ml) & 120 & 202 & 162 \\
Cold ischemic time (min) & 14 & 43 \\
Warm ischemic time (min) & 40 & 14 \\
\hline
\end{tabular}

complication. The preoperative evidence of preserved liver function and without liver cirrhosis or portal hypertension were other determinants for a good outcome. The three patients did well after the operation. In the literature reporting patients with HCC receiving ECRHA, our first patient had the longest survival $[5,7]$.

Unlike other studies, we used a temporary portocaval shunt instead of venovenous bypass to facilitate hemodynamic stability during the anhepatic period. Temporary portocaval shunts have been shown to improve hemodynamic status, reduce requirement of intraoperative blood transfusion, and preserve renal function during orthotopic liver transplantation [8]; however, it has not been reported to be used in ECHRA. We believed that the relatively short cold ischemic time and preservation of the inferior vena cava enhanced the functionality of the temporary portocaval shunt during the anhepatic period.

Table 3 Postoperative data

\begin{tabular}{llll}
\hline Post-op data & Patient 1 & Patient 2 & Patient 3 \\
\hline ICU days (days) & 8 & 7 & 8 \\
Length of stay (days) & 30 & 22 & 39 \\
Ishak score & 3 & 3 & 4 \\
Metavir fibrosis score & F2 & F2 & F3 \\
Post-op complication & 1. Sepsis & 1. Sepsis & 1. Sepsis \\
& 2. Transient hepatic & 2. Transient hepatic & 2. Transient hepatic \\
& insufficiency & insufficiency & insufficiency \\
& & & 3. Biliary leakage \\
Intervention & None & None & 4. Intra-abdominal abscess \\
Reoperation & None & None & ERCP for biliary leakage \\
Long-term follow-up & & & Laparotomy for drainage \\
Recurrence & None & In post-op 8 month & In post-op 8 month \\
$\begin{array}{l}\text { Management for } \\
\text { recurrence }\end{array}$ & None & RFA & TACE \\
Current status & Alive (28 months) & Alive (26 months) & Alive (23 months) \\
\hline
\end{tabular}

$R F A$ radiofrequency ablation, TACE transarterial chemoembolization

${ }^{a}$ Alive until May, 2013 


\section{Conclusions}

ECHRA represents an additional surgical option in the treatment of unresectable hepatic tumors, including HCC. In addition, the use of a temporary portocaval shunt is a feasible alternative to venovenous bypass during the anhepatic period.

Open Access This article is distributed under the terms of the Creative Commons Attribution Noncommercial License which permits any noncommercial use, distribution, and reproduction in any medium, provided the original author(s) and the source are credited.

\section{References}

1. Morris-Stiff G, Gomez D, de Liguori Carino N, Prasad KR. Surgical management of hepatocellular carcinoma: is the jury still out? Surg Oncol. 2009;18:298-321.

2. Gruttadauria S, Marsh JW, Bartlett DL, Gridelli B, Marcos A. Ex situ resection techniques and liver autotransplantation: last resource for otherwise unresectable malignancy. Dig Dis Sci. 2005;50:1829-1835.

3. Ikegami T, Soejima Y, Taketomi A, et al. Extracorporeal hepatic resection for unresectable giant hepatic hemangiomas. Liver Transpl. 2008;14:115-117.

4. Hemming AW, Cattral MS. Ex vivo liver resection with replacement of the inferior vena cava and hepatic vein replacement by transposition of the portal vein. J Am Coll Surg. 1999;189: 523-526.

5. Sugimachi K, Shirabe K, Taketomi A, et al. Successful curative extracorporeal hepatic resection for far-advanced hepatocellular carcinoma in an adolescent patient. Liver Transpl. 2010;16: 685-687.

6. Pichlmayr R, Grosse H, Hauss J, Gubernatis G, Lamesch P, Bretschneider HJ. Technique and preliminary results of extracorporeal liver surgery (bench procedure) and of surgery on the in situ perfused liver. Br J Surg. 1990;77:21-26.

7. Oldhafer KJ, Lang H, Schlitt HJ, et al. Long-term experience after ex situ liver surgery. Surgery. 2000;127:520-527.

8. Figueras J, Llado L, Ramos E, et al. Temporary portocaval shunt during liver transplantation with vena cava preservation. Results of a prospective randomized study. Liver Transpl. 2001;7:904-911. 